\title{
AS PRESCRIÇÕES DE AVALIAÇÃO DOS CURSOS DE FORMAÇÃO DE PROFESSORES EM EDUCAÇÃO FÍSICA
}

\author{
THE ASSESSMENT PRESCRIPTIONS IN THE INITIALS TEACHERS EDUCATION IN \\ PHYSICAL EDUCATION.
}

\section{REQUISITOS DE EVALUACIÓN DE LOS CURSOS DE FORMACIÓN INICIAL DE PROFESORES DE EDUCACIÓN FÍSICA}

\author{
Fábia Maria Boreli Poleto \\ Centro Universitário São Camilo - Brasil
}

Matheus Lima Frossard Universidade Federal do Espírito Santo - Brasil

Wagner dos Santos

Universidade Federal do Espírito Santo - Brasil

\begin{abstract}
Resumo: Este artigo busca compreender como são prescritas as práticas avaliativas em todas as disciplinas que compõem a matriz curricular de três cursos de formação de professores em Educação Física das instituições privadas do Estado do Espírito Santo e suas implicações para a constituição dos saberes docentes. Caracteriza-se como uma pesquisa qualitativa do tipo crítico-documental (BLOCH, 2001) e utiliza os planos de disciplinas como fonte. O software Iramuteq auxiliou na produção dos gráficos e na análise fatorial de correspondência. Os resultados evidenciam que os principais critérios avaliativos prescritos nos planos de disciplina estão relacionados com os aspectos: técnicos e estruturais dos trabalhos (45\%); comportamentais (40\%); do ensino ou da aprendizagem (15\%). As disciplinas de formação ampliada têm priorizado o uso de instrumentos avaliativos individuais com ênfase na escrita e na prova, enquanto as disciplinas de formação específica dão destaque à avaliação coletiva com maior diversidade de instrumentos. $\mathrm{O}$ estudo aponta para a necessidade de a formação de professores assumir práticas avaliativas que auxiliem a aprendizagem; busquem compreender os sentidos atribuídos pelos alunos às suas práticas; considerem a especificidade da disciplina; sirvam de exemplo aos alunos para futura reprodução no ambiente escolar; possibilitem a participação ativa dos discentes na escolha dos instrumentos, dos critérios e no processo de julgamento de valor e tomada de decisão.
\end{abstract}

Palavras chave: Formação inicial de professores; Avaliação; Educação Física.

Abstract: This article aims to understand how assessment practices are prescribed in all disciplines that make up the curriculum of three initial teachers education courses in Physical Education of private institutions of Espirito Santo, and its implications for the creation of knowledge teachers. It is 
characterized as qualitative research of the documentary critical type (BLOCH, 2001) and uses the plans of disciplines as a source. The Iramuteq software helped in the production of graphics and the factorial analysis of correspondence. The results show that the structural-technical aspect of the works were the main assessment criteria highlighted in the discipline plans (45\%), followed by behavioral aspects $(40 \%)$ and teaching or learning aspects (15\%). The extended knowledge disciplines have prioritized the use of individual assessment instruments with an emphasis on writing and text. Specific training subjects highlight collective assessment with a greater diversity of instruments. We pointed to the need for teacher training to take assessment practices to assist learning; seek to understand the meanings attributed by students to their practices; consider the specificity of the discipline; serve as an example to students for future reproduction in the school environment; enable the active participation of students in the choice of instruments, criteria, in the value judgment process and decision making.

Keywords: Initial teacher education; Assessment; Physical Education (PE).

Resumen: Este artículo busca comprender cómo se prescriben las prácticas evaluativas en todas las disciplinas que conforman la matriz curricular de tres cursos de capacitación docente de Educación Física en instituciones privadas en el Estado de Espírito Santo, y sus implicaciones para la constitución del conocimiento docente. Se caracteriza por ser una investigación cualitativa del tipo crítico documental $(\mathrm{BLOCH}, 2001)$ y utiliza los planes de disciplinas como fuente. El software Iramuteq ayudó en la producción de gráficos y en el análisis factorial de correspondencia. Los resultados muestran que el aspecto técnico y estructural de los trabajos fueron los principales criterios de evaluación destacados en los planes de disciplina (45\%), seguidos de los criterios de comportamiento $(40 \%)$ y relacionados con la enseñanza o el aprendizaje (15\%). Las disciplinas de capacitación extendida han priorizado el uso de instrumentos de evaluación individuales con énfasis en la escritura y el examen, mientras que las disciplinas de capacitación específicas enfatizan la evaluación colectiva con una mayor diversidad de instrumentos. Señalamos la necesidad de la formación de docentes para adoptar prácticas evaluativas que ayuden al aprendizaje; tratar de comprender los significados que los estudiantes atribuyen a sus prácticas; considerar la especificidad de la disciplina; servir de ejemplo a los estudiantes para su futura reproducción en el entorno escolar; permitir la participación activa de los estudiantes en la elección de instrumentos, criterios, en el proceso de juicio de valor y en la toma de decisiones.

Palabras clave: Formación inicial del profesorado; Evaluación; Educación Física.

\section{Introdução}

Nos últimos anos, as pesquisas realizadas nos cursos de formação de professores (MENDES, 2006; GATTI, 2014; VILLAS BOAS; SOARES, 2016) sobre avaliação têm apresentado suas análises em torno do ensino, da aprendizagem e suas características técnicas. Os autores sinalizam a necessidade de os cursos de licenciatura oportunizarem momentos de discussões no decorrer da formação acerca das concepções avaliativas, visto que sua prática na educação básica tem se limitado a pensar sua dimensão qualitativa pautada na diversificação de instrumentos, sustentada pela atribuição de notas, aplicação de provas e trabalhos em grupos. Além disso, a formação inicial articula pouco o tema com o contexto 
escolar, pensando o futuro exercício da docência e sua profissionalidade docente (NÓVOA, 1992).

Segundo Nóvoa (1992), a prática docente é tomada como espaço de construção, formação e produção dos saberes de modo formativo, o que implica assumir os saberes relativos à formação inicial de forma intimamente ligada ao conhecimento científico e à prática profissional docente - a avaliação educacional é uma delas.

No campo da Educação Física, as pesquisas sobre a avaliação educacional na educação superior (FUZI, 2010; SANTOS; MAXIMIANO, 2013; STIEG et al., 2018, SANTOS et al., 2019), que dialogam com alunos, professores e/ou com documentos curriculares, apontam também a necessidade de os cursos de licenciaturas preparar os futuros professores tendo em vista a utilização da avaliação na Educação Física, pensando suas especificidades e o processo de ensino e de aprendizagem.

A preparação dos futuros professores para a prática da avaliação está diretamente ligada: à discussão teórica sobre o tema durante a formação, seja em disciplinas específicas, seja em atividades diluídas ao longo do processo (DELUCA; KLINGER, 2010); às experiências que possibilitam ao futuro professor praticar a avaliação entre os pares (SLUIJSMANS; PRINS, 2006), com autoavaliação (KEARNEY, 2013) ou avaliando no contexto da escola (FROSSARD et al., 2018); e ao modo como são avaliados durante o processo formativo (HAMODI; LÓPEZ-PASTOR; LÓPEZ-PASTOR, 2017; PICOS; LÓPEZ-PASTOR, 2013). Neste último aspecto, os autores ressaltam que o exemplo do professor-formador é o ponto principal da constituição docente, portanto é necessário que suas práticas de avaliação acompanhem as inovações no modo de conceber a avaliação.

Entretanto, Rombaldi e Canfield (1999), em pesquisa sobre a prática pedagógica dos professores dos cursos de formação em Educação Física, concluíram que, apesar de a maioria deles terem conhecimento do que seja avaliação numa abordagem mais compatível com a progressista, isso não se materializou em mudanças nas práticas pedagógicas desses professores, ou seja, a avaliação continuava sendo realizada pela obrigação imposta e não por sua relevância. Segundo os participantes dessa pesquisa, o principal problema da avaliação educacional não está na assimilação de novos referenciais teóricos, e sim na vivência concreta desses pressupostos, pois, como afirma Martins (2002, p. 17), “[...] a escola educa mais pela forma como organiza o processo de ensino do que pelos conteúdos ideológicos que veicula”.

Nessa perspectiva, compreendemos a avaliação como ato político que se apresenta como parte do processo de tessitura de conhecimento, fundamentado na proposta da 
heterogeneidade, sem modelos fechados ou previamente definidos, uma vez que não se tem a intenção de rotular ou classificar, mas sim identificar os "saberes", os "não saberes" e o “ainda não saber” em desenvolvimento. Portanto, a tarefa do avaliador é um exercício constante de interpretar sinais e indícios a partir dos quais se manifestam juízo de valor e tomada de decisão. Pela prática investigativa, os envolvidos na ação avaliativa refinam seus sentidos e exercitam/desenvolvem diversos conhecimentos com o objetivo de agir conforme suas necessidades individuais e coletivas (SANTOS, 2005, 2008).

Assim, objetivamos, nesta pesquisa, compreender como são prescritas as práticas avaliativas em todas as disciplinas que compõem a matriz curricular de três cursos de formação de professores em Educação Física das instituições privadas do Estado do Espírito Santo e suas implicações para a constituição dos saberes docentes.

\section{Teoria e Método}

Este estudo caracteriza-se como uma pesquisa qualitativa do tipo crítico-documental (BLOCH, 2001). Não nos interessou julgar o que tem sido prescrito. Nosso objetivo é interrogar, interpretar e comparar as fontes, entendendo-as como artefatos culturalmente construídos e repletos de intencionalidade (BLOCH, 2001), pois, ao utilizar os planos de curso e de disciplina como fonte de pesquisa, compreendemos, por meio de pistas e indícios (GINZBURG, 1989), as intencionalidades das instituições na proposição do tema avaliação que, neste caso, são os currículos prescritos (SACRISTÁN, 2000) dos cursos de formação de professores em Educação Física das instituições privadas do Estado do Espírito Santo.

No que se refere aos critérios para delimitarmos as instituições participantes, consideramos: a) ser uma instituição de ensino superior privada do Espírito Santo; b) ter o curso de Licenciatura em Educação Física na modalidade presencial; e c) manifestar interesse de participar da pesquisa. A preferência pelas instituições privadas justifica-se pelo quantitativo de professores formados por elas e por seu grande impacto no contexto do Espírito Santo, que tem $94 \%$ dos cursos de Educação Física ofertados por instituições privadas. Outra justificativa deve-se ao fato de esta pesquisa estar inserida dentro do projeto "Ensino da avaliação educacional na formação de professores em Educação Física da América Latina”, desenvolvido pelo Instituto de Pesquisa em Educação e Educação Física (Proteoria), que teve sua primeira fase voltada às universidades públicas nacionais e, neste momento, tem ampliado o olhar para as instituições privadas e para o contexto da América Latina. 
Das 16 instituições, 6 não aceitaram o convite, 7 não responderam e 3 participaram. São elas: a Escola Superior São Francisco de Assis (Esfa); a Faculdade Vale do Cricaré (FVC); e a Universidade Vila Velha (UVV). Após contato com os coordenadores, realizamos visitas in loco para explicar os objetivos da pesquisa, esclarecer dúvidas, solicitar e coletar as fontes. De modo específico, utilizamos como fonte os planos de disciplinas, que assim estão distribuídos: ESFA (54), FVC (54), UVV (56).

Categorizamos as fontes considerando a relação das disciplinas por área de conhecimento, segundo a Resolução CNE/CES no 7/2004, que propõe que os currículos de formação de professores de Educação Física sejam constituídos tanto por áreas de conhecimento de formação ampliada como de conhecimentos específicos.

As disciplinas de formação ampliada são divididas em: a) Relação ser humanosociedade, que compreende os conhecimentos históricos, sociológicos, ético-políticos, filosóficos, religiosos e culturais; b) Biológica do corpo humano, na qual foram relacionadas as disciplinas que permitem entender o movimento a partir dos aspectos biológicos, fisiológicos, anatômicos, biomecânicos, entre outros; c) Produção do conhecimento tecnológico e científico, que se encontra atrelada à realização de pesquisas e aplicações dos conhecimentos de comunicação acadêmica escrita e oral da língua portuguesa, da informática e dos conhecimentos básicos de estatística.

As disciplinas de formação específica são divididas em: a) Didático-pedagógica, que aborda conhecimentos dos princípios gerais e específicos de gestão e organização da intervenção do profissional no campo de trabalho e de formação, por exemplo: o estágio supervisionado, didática e pensamento pedagógico; b) Cultural do movimento humano, composta por disciplinas da Educação Física relacionadas com o jogo, a brincadeira, as lutas, a dança, os esportes e a ginástica; c) Técnico-instrumental, que reúne conhecimentos sobre as bases teóricas e metodológicas aplicadas ao desenvolvimento humano, ao comportamento motor, à psicologia etc., que irão instrumentalizar o profissional para sua atuação.

O banco de dados foi inserido no software Iramuteq auxiliando na análise fatorial de correspondência, que permitiu o cruzamento entre o vocabulário (considerando a frequência de incidência de palavras) e as classes, gerando uma representação gráfica em plano cartesiano, na qual são vistas as oposições entre classes ou formas (NASCIMENTO; MENANDRO, 2006).

Conforme Ginzburg (1989), foi possível identificar, por meio das palavras, as práticas avaliativas assumidas por área de conhecimento e pelas instituições. É preciso destacar que o 
software Iramuteq não foi usado como método, portanto seus relatórios não constituem por si uma análise. Concordamos com Bloch (2001, p. 79) sobre a necessidade de o pesquisador assumir uma atitude ativa, “[...] pois os textos ou os documentos arqueológicos, mesmo os aparentemente mais claros e mais complacentes, não falam senão quando sabemos interrogálos". Assim, exploramos os planos de disciplinas analisando as pistas e os indícios (GINZBURG, 1989) deixados pelas fontes e as intencionalidades de quem os produziu.

Todos os planos de disciplina foram lidos na íntegra para a criação do banco de dados. Para identificação das práticas avaliativas, copiamos dos planos de cada disciplina as informações do tópico avaliação e as inserimos em um documento de blocos de notas. Nesse processo, categorizamos as informações de acordo com a área de conhecimento, o título das disciplinas e a instituição pertencente. Na criação desse corpus documental, foram excluídas as pontuações e as palavras compostas foram unidas por um traço baixo para que o software as reconhecesse como termos únicos, com sentido próprio e contabilizasse sua frequência de aparecimento. Após a inserção do documento no software Iramuteq, realizamos o procedimento de eliminar as "palavras vazias", que não atribuem sentido ao texto. Destacamos que, entre as palavras que comporiam as análises, excluímos preposições, verbos de ligação e advérbios.

Para melhor apresentação dos dados, os gráficos produzidos pelo software Iramuteq foram convertidos para o formato CSV e reorganizados no software Excel por área de conhecimento. O Gráfico 1 é responsável em dar visibilidade aos critérios avaliativos, e o Gráfico 2 se volta para os instrumentos.

\section{Análise dos dados}

No intuito de compreender quais práticas avaliativas têm sido prescritas pelos cursos de formação de professores em Educação Física, analisamos os planos de 164 disciplinas que compunham os cursos e elaboramos dois tópicos de análise: a) os critérios avaliativos; b) os instrumentos avaliativos.

\section{Os critérios avaliativos prescritos nos planos de disciplina}

O Gráfico 2, organizado por área de conhecimento, busca evidenciar os critérios que tiveram maior quantidade de citações nos planos de disciplina. 
Gráfico 2 - Critérios avaliativos por área de conhecimento

\begin{tabular}{l}
17 \\
\hline
\end{tabular}

Ser Humano e Sociedade
Biológica do Corpo Humano

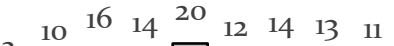

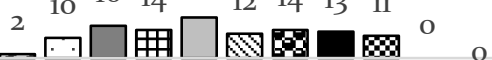

Produção do Conhecimento Técnico e Científico

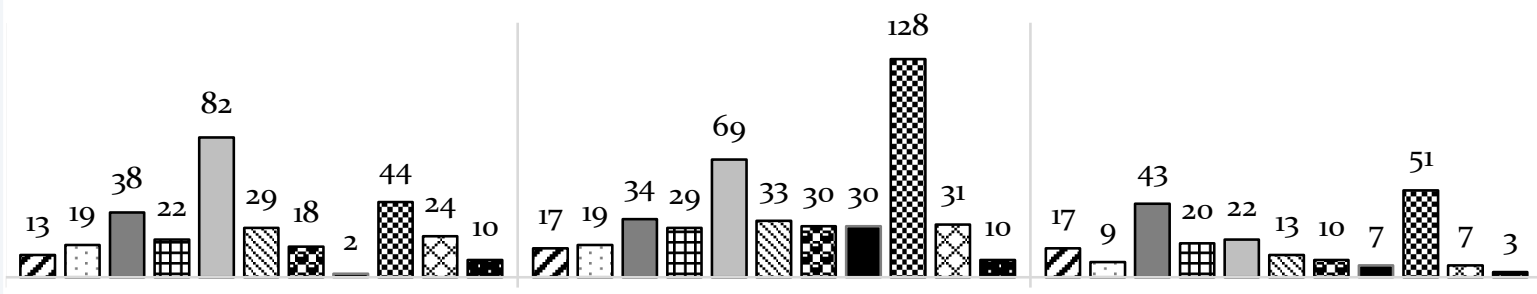

Didático-Pedagógico

Cultural do Movimento Humano

Técnico-Instrumental

$\square$ a) Capacidade de argumentação, síntese e articulação do conhecimento

$\square$ a) Domínio do conteúdo/conceito

$\square$ b) Apresentação

田) Clareza; coerência; coesão

口b) Elaboração; postagem; entrega; realização uma tarefa

母b) Normas da ABNT; estrutura e qualidade estética do texto; ortografia; linguagem

(c) Assiduidade; presença; pontualidade

घc) Cumprimento de horários e prazos

ⓒ) Participação; envolvimento; interesse; comprometimento

曰c) Planejamento; organização; execução nas intervenções

- c) Postura profissional e pedagógica

Fonte: Os autores.

Os critérios avaliativos podem ser entendidos como um quadro de referência sobre o que deve ser levado em conta nesse processo de juízo de valor. Ao responder sobre o que deve ser avaliado, os planos de disciplina têm evidenciado uma diversidade de critérios que foram categorizados em: a) o ensino e a aprendizagem de um conteúdo; b) a técnica e a estrutura dos trabalhos; c) o comportamento dos alunos.

A primeira categoria, avaliação do ensino e da aprendizagem de um conteúdo, foi destacada por disciplinas de todas as áreas de conhecimento. Corresponde a 15\% dos critérios de avaliação prescritos nos planos de ensino e têm como preocupação avaliar o domínio do conteúdo ou o conceito e a capacidade de o aluno argumentar, articular ou sintetizar os conhecimentos. 
Vemos nessa categoria uma preocupação em definir critérios referentes aos conteúdos. Cabe ressaltar que essa avaliação está diretamente relacionada com a avaliação do ensino e as práticas do professor, que, mesmo valorizando as ações dos alunos, o objetivo e a centralidade estão em fornecer-lhes um retorno dos seus processos de ensino. Percebemos, nesse movimento, que há uma ação que visa a identificar o que o aluno aprendeu, com foco no ensino do professor. Entendemos, com isso, a necessidade de se conseguir informações em relação ao que é ensinado, analisando os resultados obtidos com base nessa ação (STIEG et al., 2018). Essa análise limita-se, portanto, em compreender o que o aluno sabe daquilo que foi ensinado.

Desse modo, um dos critérios destacados nessa categoria foi o domínio do conteúdo ou conceito, como podemos observar nas descrições dos planos de algumas disciplinas:

Levantamento do conhecimento atual dos alunos a respeito dos conteúdos da disciplina (Práxis das Lutas, ESFA).

Avaliação escrita sobre conteúdos das unidades I e II (Fisiologia, ESFA).

Prova Institucional com questões objetivas e discursivas relacionadas ao conteúdo curricular estudado (Filosofia da Educação Física, FVC).

Avaliação discursiva observando a compreensão das aulas expositivas e a organização do conteúdo (Psicologia da Educação, FVC).

Desempenho em uma avaliação escrita a cada bimestre sobre o conteúdo trabalhado [...] (Bases Filosóficas das Atividades Corporais e Esportivas; História da Educação Física e do Esporte, UVV).

Trabalhos escritos tendo como foco os conteúdos de ensino abordados (Bases Sociológicas das Atividades Corporais; Legislação e Ética, UVV).

Essa questão é encontrada nos planos das disciplinas das duas áreas de conhecimento, entretanto tem maior peso nas disciplinas de formação ampliada devido à menor variedade de critérios avaliativos e à maior ênfase na "aferição" do domínio do conteúdo pelo aluno.

Não desconsideramos a importância do conteúdo, mas entendemos a necessidade de assumir uma avaliação que busque compreender o sentido que os alunos atribuem à sua aprendizagem, identificando a relação que eles estabelecem com o saber e os significados produzidos (SANTOS et al., 2014). Esse processo é construído com base em um exercício permanente de interpretação dos indícios, em que se busca identificar os "saberes" os "não saberes" e "ainda não saberes" em desenvolvimento (ESTEBAN, 1999). Configura-se, assim, como um processo de reflexão sobre e para a ação, contribuindo para que o professor e o aluno se tornem capazes de perceber indícios, de atingir níveis de complexidade na interpretação de seus significados e de incorporá-los como eventos relevantes para a dinâmica do ensino-aprendizagem (SANTOS, 2005). 
É preciso destacar um outro movimento formado por disciplinas tanto da área de conhecimento ampliado como também do âmbito específico, que apresenta a preocupação de entender o modo como o aluno tem articulado os seus aprendizados sobre os conteúdos ensinados:

Criação e desenvolvimento de um jogo em trios explorando conceitos e ideias filosóficos [...]. Critérios: caráter lúdico da atividade; presença de conceitos e/ou ideias filosóficas associadas ou não a seus autores; capacidade individual de análise e síntese dos textos lidos e debates promovidos; postura e capacidade de organização da atividade e da turma [...] (Filosofia, ESFA).

O objetivo principal dessa atividade avaliativa é capacitar o acadêmico a planejar uma aula, de maneira sistemática, aproximando os conteúdos das disciplinas de sua formação acadêmica com os conteúdos específicos da Educação Física. Como critérios avaliativos serão: capacidade de síntese; sistematização e articulação de conhecimento [...] (Biologia Celular, ESFA). A elaboração de vídeo referente no formato de YouTube será desenvolvida como forma de estimular a articulação dos conhecimentos produzidos na disciplina, com a práxis docente do professor de educação física. O objetivo principal dessa atividade avaliativa é buscar diferentes linguagens para articular os conhecimentos produzidos na disciplina (Fisiologia, ESFA).

Serão avaliados: [...] a prática de ensino em Educação Inclusiva; o planejamento; e a docência interdisciplinar com Práticas Pedagógicas (aula planejada e desenvolvida pelos discentes e aplicada na Apae de São MateusES) (Educação Física na Perspectiva da Inclusão, FVC).

A avaliação será realizada mediante aplicação de provas teóricas e práticas e trabalhos didáticos individuais e em grupos criando situações problemas e casos práticos a serem resolvidos pelo aluno (Futebol, UVV).

Os planos dessas disciplinas têm destacado a necessidade de avaliar levando em consideração a capacidade de os alunos articular os conceitos aprendidos na disciplina com os conteúdos de ensino da Educação Física e saberes da atuação profissional. Esse movimento amplia as possibilidades de pensar a avaliação no contexto da formação de professores, principalmente nas disciplinas de formação ampliada que não lidam diretamente com o ensino dos saberes pedagógicos ou com a prática de ensino. Ao criarem um jogo, planejarem uma aula, elaborarem um vídeo, ministrarem uma aula ou resolverem uma situação-problema, os alunos têm de ser capazes de articular diferentes saberes e habilidades, organizando seus aprendizados de maneira prática, semelhante às situações cotidianas de atuação profissional.

Destacamos a necessidade de todas as disciplinas que compõem o currículo pensarem a formação para atuação profissional. Desse modo, devem possibilitar e incentivar momentos em que os alunos exercitem a função docente e desenvolvam a capacidade de articular os diferentes saberes aprendidos durante o curso.

Dentre a diversidade de critérios avaliativos apresentados nos planos de disciplinas, identificamos que $45 \%$ estão relacionados com a avaliação da estrutura técnica dos 
trabalhos. Dentre eles, são citadas avaliações da apresentação, clareza, coerência, construção, escrita, estrutura, elaboração, entrega, postagem e qualidade. Esses critérios são destacados por todas as áreas de conhecimento, tendo maior peso nas disciplinas que abordam a produção do conhecimento tecnológico, científico e didático-pedagógica.

É de grande importância que o incentivo à prática da escrita e ao desenvolvimento da capacidade de redigir textos científicos seja uma das propostas da formação de professores e, consequentemente, que avaliem questões como: expressão e clareza dos textos; objetividade da formulação das ideias; respeito à língua portuguesa; normatização de textos; técnicas de produção; pontualidade na entrega; e elaboração de artigos de caráter científico.

Ao exercitar a escrita ou a apresentação oral de uma pesquisa, tem-se a oportunidade de sintetizar e expressar os sentidos e significados atribuídos ao seu aprendizado durante o processo. Nesse movimento, é possível conhecer o sujeito que a produz, suas ideias, suas crenças, seus valores, seu contexto histórico-cultural e a forma como manifesta seu pensamento.

Destacamos a Resolução CNE/CES n ${ }^{\circ} 7 / 2004$, que garante a oferta de disciplinas sobre a produção do conhecimento tecnológico e científico nos cursos de formação de professores. Alinhadas a essa resolução, Esfa, FVC e UVV têm ofertado disciplinas que abordam esse conhecimento e, consequentemente, adotam práticas avaliativas que valorizam e favorecem a aprendizagem desses critérios. Entretanto, a preocupação de avaliar os aspectos técnico-estruturais da construção dos textos e o uso da escrita e da pesquisa científica como instrumento de avaliação não são exclusividade dessas disciplinas.

Essas ações também são visíveis nos planos de Estágio Supervisionado, Fundamentos da Educação Física, Práxis do Lazer, Práxis dos Esportes Individuais, Políticas Públicas e Legislação Educacional da Esfa. Elas propõem avaliar a elaboração de artigo, apresentação escrita do relatório de pesquisa e critérios como "elaboração do banner e apresentação final do artigo"; "pontualidade e frequência das postagens"; "adequações às normas da ABNT"; "escrita à caneta e ausência de rasuras".

Na FVC, os planos de disciplina de Capoeira na Escola, Determinantes Citológicos e Histológicos do Movimento Humano, Didática Geral, Esportes Paraolímpicos e Socorros de Urgência em Ambientes Escolares prescrevem avaliar a organização das ideias por meio de texto escrito sobre a temática e, como critério de avaliação, a "qualidade técnica dos trabalhos (argumentação, criatividade, coerência, redação etc.)" "formatação" e "pontualidade de postagem”. Já na UVV, as disciplinas Avaliação Educacional e Estágio Supervisionado 
sinalizam avaliar a produção de artigo científico, observando a "produção e entrega de texto escrito", "coesão e coerência textual”.

Surgem nesse debate dois questionamentos. Um primeiro: o que se quer avaliar ao usar um determinado instrumento? Ou seja, ao pedir que o aluno escreva um texto/artigo, realizar uma pesquisa ou um trabalho escrito, o que se pretende avaliar? Quais devem ser os critérios avaliativos e quais devem ter maior valor? Temos observado que, nos planos de disciplina dessas instituições, há uma grande preocupação em descrever os critérios avaliativos relacionados com a estruturação técnica dos textos, trabalhos e artigos, e poucos critérios associados propriamente à análise dos conteúdos dos trabalhos escritos e das aprendizagens dos alunos. Nesse sentido, fica evidente, na descrição dos critérios avaliativos, um movimento que dá maior peso ao cumprimento da tarefa dentro do prazo e dos padrões estéticos previamente estabelecidos do que ao próprio conteúdo textual.

Tendo em vista os critérios avaliativos valorizados pelos professores ao usarem o artigo científico como instrumento de avaliação, surge um segundo questionamento: qual o propósito de seu uso em disciplinas que não são da área de produção do conhecimento tecnológico e científico?

Segundo, Mendes (2006) e Fuzii (2010), a avaliação no ensino superior tem apresentado a tradição de usar instrumentos e critérios que valorizam unicamente os aspectos teóricos, pela utilização de provas e trabalhos escritos. Não se trata aqui de nomear determinado critério e instrumento como vilão, mas concordamos com Fuzii (2010) sobre a urgência de novas maneiras de se avaliar que estejam compatíveis com o saber valorizado pela disciplina, a realidade multicultural das universidades e com as práticas democráticas.

Temos entendido, assim como Frossard et al. (2018) e Santos et al. (2018), a necessidade de assumir outras práticas avaliativas que considerem o tipo de saber valorizado pelas disciplinas, em virtude da natureza daquilo que é ensinado. Esses estudos têm evidenciado que disciplinas, como Artes, Educação Física e Música, estabelecem outra relação com o saber, valorizando distintas maneiras de aprender, para além da fala e da escrita, sendo necessária uma avaliação que dê visibilidade a esses aprendizados.

Ao ser avaliado, o aluno também aprende sobre avaliação e apropria-se de práticas para a docência futura. Dessa forma, entendemos que as disciplinas do curso de formação de professores podem estimular práticas avaliativas que: a) auxiliem a aprendizagem; b) busquem compreender os sentidos atribuídos pelos alunos às suas práticas; c) considerem a especificidade da disciplina; d) sirvam de exemplo aos alunos para futura reprodução no 
ambiente escolar; e) possibilitem a participação ativa dos alunos na escolha dos instrumentos, critérios, no processo de julgamento de valor do seu próprio aprendizado e dos colegas e na tomada de decisões.

É preciso destacar que o uso de critérios comportamentais correspondeu a $40 \%$ do total e eles não foram exclusividade de algumas disciplinas, porém foram prescritos nos planos das disciplinas de conhecimento ampliado, como também de conhecimento específico. Nesse movimento, todas as instituições destacaram avaliar a: participação, interesse, postura, envolvimento, pontualidade e assiduidade.

Conforme Darido (2011), os professores têm utilizado critérios relacionados com a participação, o interesse e a frequência dos alunos, devido ao fato de a formação inicial não ter possibilitado uma reflexão de suas práticas avaliativas vividas na educação básica e, dessa forma, repetem em sua atuação os mesmos métodos avaliativos. No que diz respeito ao uso de critérios avaliativos, como assiduidade e envolvimento, seja nas aulas, seja nas atividades propostas, estudos de Cechella (1991), Santos (2005), Siebert (1995), Rombaldi e Canfield (1999) indicam que o fato de o aluno estar matriculado e disposto a assistir à aula não pode servir de critério para a prática avaliativa. Santos $(2005$, p. 136) ressalta, ainda, “[...] que esse critério é, em sua plenitude, uma inversão total de valores, pois o mínimo esperado do aluno passa a ser critério para sua aprovação".

Frossard et al. (2018) sinalizam outro olhar sobre o uso da participação como critério avaliativo no contexto da formação de professores. Na medida em que permite aos alunos atribuir juízo de valor às suas aprendizagens, privilegia a participação como um saber a ser aprendido nas aulas, além de proporcionar diagnóstico da prática pedagógica ao professor e ao aluno. Ou seja, avalia-se a participação entendendo a necessidade de o aluno em formação assumir uma postura ativa de protagonista, com constante autoavaliação das suas atitudes e aprendizagens, assim como o professor reorganizar suas ações de ensino.

É interessante notar que, quando cruzamos o período em que esses estudos foram realizados, entre 1991 e 2018, com o ano em que foram produzidos os dados para este artigo, as prescrições de avaliação dos planos de ensino sinalizam uma permanência desses critérios de natureza comportamental como definidores do que deve ser avaliado na Educação Física. Contudo, é preciso considerar as disciplinas em que esses critérios são mais empregados.

Ao analisarmos aquelas que destacaram o uso de critérios comportamentais, foi possível agrupá-las em três grupos de acordo com sua função. O primeiro grupo apresenta disciplinas de todas as áreas de conhecimento e destaca avaliar os aspectos comportamentais 
como forma de controle do corpo dos alunos, favorecendo o desenvolvimento das aulas, por exemplo,

A pontuação será dada mediante a participação efetiva, presença e comportamento do aluno em todos os dias do Fórum de Experiência (Fisiologia do Exercício, ESFA).

Além do cumprimento das tarefas solicitadas, será avaliada em cada aula a qualidade da participação no processo de ensino aprendizagem, basicamente: assiduidade, presença e cumprimento de horários, leitura dos textos, empenho na realização das tarefas solicitadas, participação efetiva nas discussões, contribuindo com questões, ideias e informações relevantes, respeito às características e opiniões do outro e a colaboração com os colegas (Seminário de Monografia II, ESFA).

Leitura dos textos e participação nos debates [...] (Educação Física na Educação Básica, UVV).

As narrativas demonstram como a avaliação tem sido usada como mecanismo de poder e controle dos corpos, fazendo com que os alunos participem e cumpram tarefas básicas para o desenvolvimento das aulas, tais quais: participação nos debates, leitura dos textos, respeito ao próximo, presença e assiduidade.

A prática avaliativa relacionada com a verificação dos comportamentos e atitudes dos alunos associa-se à ideia de disciplina que faz "[...] funcionar o espaço escolar como uma máquina de ensinar, mas também de vigiar, de hierarquizar, de recompensar" (FOUCAULT, 1977, p. 134). A disciplina constitui um elemento intraescolar que sustenta a escola, definido por Foucault (1997, p. 118) como "[...] métodos que permitem o controle minucioso das operações do corpo, que realizam a sujeição constante de suas forças e lhes impõem uma relação de docilidade-utilidade".

Entretanto, é preciso compreender que muitos desses comportamentos ainda estão associados aos modelos de educação que os estudantes vivenciaram durante sua educação básica, como pouca participação e interação nos processos de ensino e de aprendizagem. Pascarella e Terenzini (2005) alertam para o fato de muitos estudantes estarem no fim da adolescência ou no início da etapa de adulto-jovem e destacam que, ao ingressar no ensino superior, eles passam por um grande processo de transição e adaptação aos ambientes de ensino e aprendizagem menos alicerçado em livros ou apostilas, com maior iniciativa, independência e autonomia na aprendizagem. Nesse sentido, os autores destacam que o primeiro ano de graduação é fundamental para aumentar o nível de participação, integração e de satisfação dos discentes com o curso.

Os critérios prescritos nos planos de ensino têm revelado aquilo que os professores consideram como mais importante de ser aprendido pelos estudantes e, consequentemente, 
avaliado nos cursos de formação inicial. Entretanto, entendemos que a participação, presença, assiduidade e cumprimento de horários são comportamentos mínimos necessários para um bom ambiente de aprendizagem e, portanto, não deveriam ser critérios de avaliação nos cursos de formação inicial de professores. Destacamos que os processos avaliativos precisam levar os alunos a refletir sobre seus comportamentos para que possam tomar decisões que favoreçam uma nova postura, mas não devem ser usados como instrumento de controle e poder.

No segundo grupo, encontramos, principalmente, as disciplinas de conhecimento específico da área Cultural do Movimento Humano. De modo geral, os conteúdos dessas disciplinas devem ser apropriados pelos alunos para, futuramente, ao se tornarem professores, serem ensinados nas escolas. Semelhantes ao primeiro grupo, os critérios comportamentais foram usados como forma de incentivar o envolvimento e a participação dos educandos, porém evidenciaram a necessidade de envolvimento deles nos momentos de prática.

A avaliação será contínua e cumulativa, levando-se em consideração: a participação, o interesse e comprometimento com as atividades propostas [...], a utilização de roupas adequadas para a prática, o zelo pelo espaço físico, instalações e materiais [...] (Ginástica Artística, UVV).

[...] os critérios de avaliação serão: a participação ativa nas aulas (teóricas e práticas), a assiduidade, pontualidade, questionamentos fundamentados nos textos para debate, a vestimenta correta para a prática de atividades esportivas e equipamentos de segurança obrigatórios. Lembrando que, de acordo com a resolução da ESFA, o aluno que não estiver trajado com a vestimenta adequada ficará impedido de permanecer no ambiente de aula, até mesmo para assistir [...] (Práxis das Lutas, ESFA).

Observação do desempenho e da participação do aluno durante as aulas, a utilização de vestimenta adequada à prática [...] (Práxis do Atletismo, FVC).

Essas disciplinas destinam parte de suas cargas horárias ao desenvolvimento de atividades práticas, entretanto, em muitos casos, há pouco envolvimento e participação dos alunos nesses momentos, inviabilizando sua realização. Nos fragmentos dos planos de disciplina, os professores têm usado esses critérios de avaliação comportamental como troca para maior engajamento, assim como destacam a necessidade de vestimenta adequada para a realização das aulas práticas, cuidado com locais e materiais.

Gimenez (2011) ressalta que as concepções de formação de professores focadas em "aprender a fazer" e/ou "aprender a ensinar" podem não ser suficientes para as demandas atuais da educação básica. Ou seja, para o autor, tanto dominar corporalmente os conteúdos da cultura de movimento, assim como saber os aspectos didáticos e metodológicos de ensino não são suficientes, se não estiverem articulados ao contexto de atuação (escola), à pesquisa e ao 
envolvimento do estudante no processo. Nesse sentido, fazem-se necessárias outras ações de responsabilização do estudante, para além da avaliação, com a finalidade de desenvolver o protagonismo do aluno nos processos de aprendizagem.

Especificamente, a produção de conhecimentos na Educação Física é pautada pela experiência dos praticantes com os conteúdos práticos. Experiência essa que se constitui na ideia do fazer com, conforme afirmam Schneider e Bueno (2005). Para os autores, os conteúdos com os quais essa disciplina lida são atividades constantemente submetidas a minivariações de situações de aprendizagem, considerados, em muitos momentos, menos dignos do universo da cultura escolar, já que escapam aos saberes privilegiados pela escola: a fala e a escrita. Os alunos, ao inscreverem um tipo de saber em seu corpo, tornam-no pertencente a si próprios e quanto mais dele se apropriarem e o usarem em vários ambientes e contextos subjetivos, maior será a dificuldade em verbalizá-lo em forma de enunciado, "o falar de".

Assim como Nóvoa (2017), entendemos que a formação de professores deve estar inserida no contexto organizacional da profissão, favorecendo um processo de construção da identidade profissional que se coloca num campo de forças e de poderes em que cada um constrói a sua posição em relação consigo mesmo e com os outros. Desse modo, as posições assumidas pelos corpos nas aulas evidenciam também “[...] o processo como cada um se torna profissional” (NÓVOA, 2017, p. 1119).

Assumimos, como perspectiva de corpo, o relacionar-se com um conjunto de significados e de linguagens presentes no mundo, por meio dos quais se estabelecem relações interpessoais e se constitui um corpo-sujeito dono de si mesmo e do seu ambiente (CHARLOT, 2000). Embora reconheçamos as implicações dos aspectos biológicos na concepção do que seja o corpo, é por meio da relação estabelecida entre esse corpo-sujeito com as práticas, consigo mesmo e com o outro que há a incorporação e a expressão de um conteúdo materializado em um corpo biológico, que não se encontra, porém, desarticulado de sentidos culturais, sociais, históricos e das próprias identidades. Dessa forma, a participação ativa dos alunos passa a ser parte fundamental no processo educacional, que, no caso da formação de professores de Educação Física, perpassa também pela aprendizagem prática dos conteúdos a serem ensinados.

No último grupo, identificamos disciplinas de formação específica tanto de cunho didático-pedagógico, como também cultural do movimento humano. A avaliação dos aspectos 
comportamentais nessas disciplinas está ligada a momentos de atuação docente, nos quais são exigidos e assumidos comportamentos relativos à profissão professor.

Postura profissional, que envolve os seguintes aspectos: pontualidade; assiduidade; relacionamento interpessoal (alunos x estagiário; estagiário x professor da escola; estagiário $\mathrm{x}$ estagiário; estagiário $\mathrm{x}$ professor de Estágio); [...] (Estágio Escolar I, UVV).

Elaboração de projeto e execução de um evento esportivo (Atletismo, UVV). Postura pedagógica na condução das intervenções [...] (Metodologia do Ensino da Educação Física, FVC).

Organização da aula e postura pedagógica na condução da atividade (Teoria e Prática da Ginástica Geral, FVC).

Também será avaliada a participação do aluno na organização do evento e na produção e aquisição dos figurinos (Práxis da Dança, ESFA).

Os fragmentos dos planos de ensino estão associados a momentos de atuação profissional do estudante durante a sua formação e destacam critérios para avaliar atitudes e comportamentos que julgam necessários à profissão, como: postura, organização, condução e comprometimento. Vemos, por exemplo: no plano da disciplina Teoria e Prática da Dança (FVC), a preocupação de avaliar a "simulação docente com o conteúdo dança"; no plano da disciplina Práxis dos Esportes de Aventura (ESFA), a avaliação da "organização dos alunos na elaboração de festivais"; e na disciplina Educação Física Diversidade e Inclusão (UVV), a avaliação do "comprometimento dos alunos na condução das atividades".

Esse movimento evidencia que os cursos têm se preocupado em formar o sujeito não apenas pensando no domínio e conhecimento do conteúdo, mas também no próprio campo de atuação, produzindo práticas referentes à postura profissional, elaboração e condução de aulas, presentes, principalmente, nas disciplinas de formação específica.

Esse processo de aproximação do estudante com o ambiente profissional e a utilização de critérios avaliativos, que valorizam a necessidade de o aluno assumir o papel de professor durante a formação, proporcionam a construção de sua identidade profissional, pois não se pode construí-la "[...] fora de um contexto organizacional e de um posicionamento no seio de um coletivo que lhe dê sentido e densidade".

Assim, interessa que a formação inicial proporcione "[...] a incorporação de um conjunto de disposições duradouras, e a possibilidade de este patrimônio ser transferível através de um processo de socialização profissional" (NÓVOA, 2017, p. 1118-1119). Para Nóvoa (2017), a formação de professores exige contato com a profissão. Portanto, a prática docente constitui-se um momento decisivo e um dos mais significativos da formação e, em muitos casos, a primeira experiência dos estudantes com a profissão. 


\section{Os instrumentos avaliativos prescritos nos planos de disciplina}

A partir da análise das práticas avaliativas prescritas nos planos de disciplina, construímos o Gráfico 3, identificando os instrumentos avaliativos mais citados em cada área de conhecimento.

Gráfico 3 - Instrumentos avaliativos por área de conhecimento

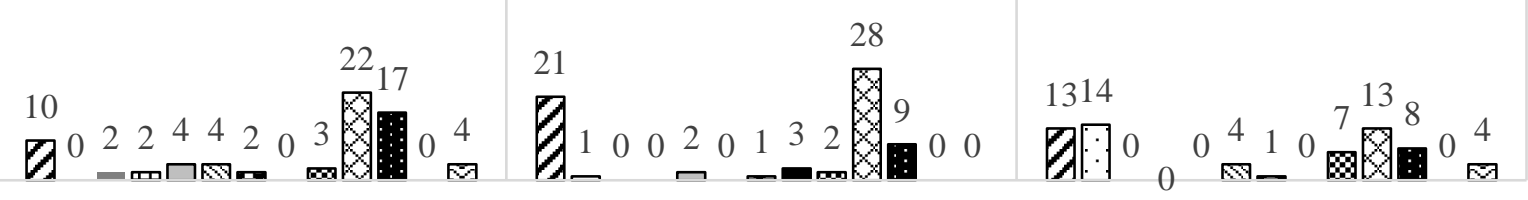

Ser Humano e Sociedade

Biológica do Corpo Humano

Produção do Conhecimento Ténico e Científico

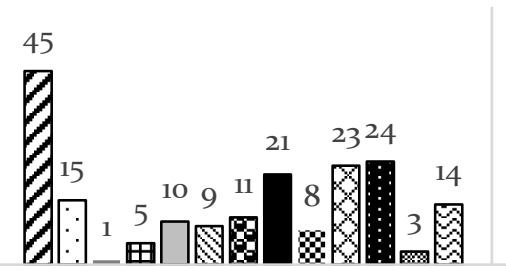

Didático-Pedagógico

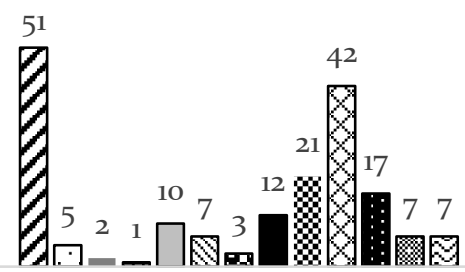

Cultural do Movimento Humano

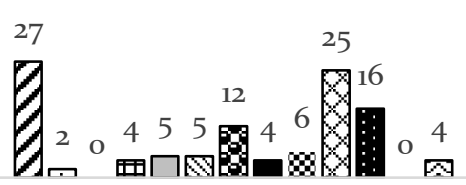

Técnico-Instrumental

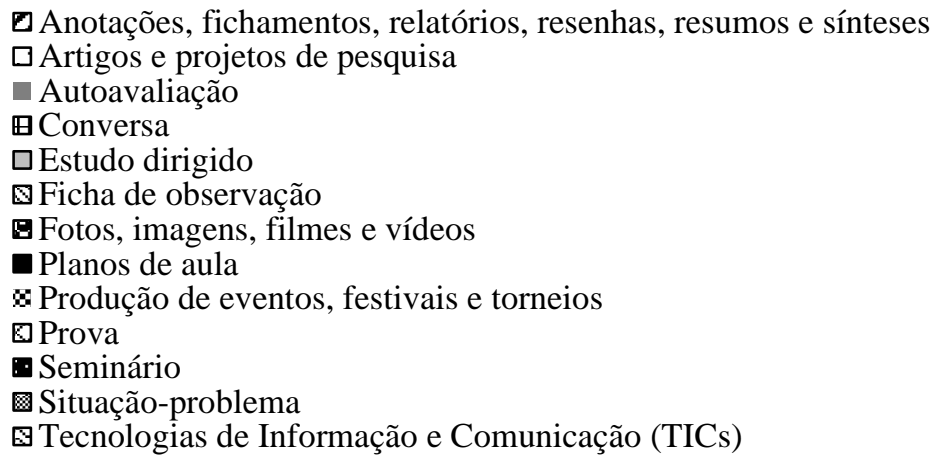

Fonte: Os autores.

Temos entendido os instrumentos avaliativos como metodologia que possibilita tanto o aluno quanto o professor resgatarem uma memória do processo de ensino e de aprendizagem (HOFFMANN, 2002). Eles devem estar em consonância com a perspectiva de educação assumida pelo professor, considerando a natureza do componente curricular, os métodos e os procedimentos utilizados durante as aulas, assim como as características dos alunos.

De modo semelhante aos estudos de Mendes (2006), Fuzii (2010) e Frossard et al. (2018), nossa pesquisa também evidenciou que o uso da prova, do seminário e de trabalhos escritos continua sendo os principais instrumentos avaliativos empregados nos cursos de formação de professores em Educação Física. Entretanto, precisamos relativizar seu peso 
dentro das áreas de conhecimento, pois, quando analisamos o valor dado à prova teórica nas disciplinas de formação ampliada, percebemos que houve 63 citações, correspondendo a 32\% do total de instrumentos citados naquela área. Já nas disciplinas de formação específica, esse peso é menor, 90 citações, representando $17 \%$.

Ao cruzarmos os instrumentos destacados por todas as áreas de conhecimento com os critérios avaliativos, identificamos um grupo de instrumentos voltados à avaliação apenas individual do aluno, outros transitam entre critérios individuais e coletivos e um grupo de instrumentos que destaca apenas o coletivo.

Nesse primeiro grupo, ganham destaque os instrumentos anotação, fichamento, relatório, resenha, resumo, síntese, autoavaliação, estudo dirigido e prova, por avaliar individualmente os alunos. A prova e os trabalhos escritos têm sido relacionados com os critérios de avaliação do conteúdo e seu uso foi destacado por todas as áreas do conhecimento, tendo maior peso nas disciplinas de cunho Biológico do Corpo Humano.

De maneira geral, percebemos um movimento em que, mesmo utilizando instrumentos avaliativos que envolvam a participação direta dos alunos no processo, eles são orientados pelo professor. O processo de juízo de valor está primordialmente na centralidade do professor.

De maneira inversa aos demais instrumentos destacados nesse grupo, a autoavaliação envolve julgamento dos alunos sobre seu próprio aprendizado, suas realizações e seus resultados (KEARNEY, 2013). Para Sluijsmans e Prins (2006) e Boud, Cohen e Sampson (1999), ela pode: fornecer motivação; influenciar o engajamento e desempenho acadêmico; proporcionar maior autonomia; e auxiliar no estabelecimento de novas metas de aprendizagem.

Em pesquisa realizada por Kearney (2013), os alunos destacaram que a falta de formação e de adoção de princípios norteadores fez com que a autoavaliação fosse um processo problemático, estressante e com abordagens superficiais, mencionando a possibilidade de subestimar-se o/ou trapacear. Como solução, a autora recomenda a construção de critérios e objetivos com a participação dos alunos para melhorar a qualidade desse processo.

Entendemos que esse instrumento fornece a possibilidade de o estudante em formação ter prática com a avaliação, contribuindo para sua autonomia e pensamento crítico, estabelecendo um juízo de valor sobre seu próprio envolvimento e aprendizado, além de 
favorecer o reconhecimento do seu lugar nesse processo para uma tomada de decisão que favoreça futuras aprendizagens.

É preciso destacar que a autoavaliação foi usada apenas em seis disciplinas da UVV (Bases Filosóficas das Atividades Corporais e Esportivas; História da Educação Física e do Esporte; Estágio Profissional; Tópicos Especiais em Educação Física e Esportes; Atletismo; e Metodologia dos Esportes Individuais) e não observamos a presença de instrumento que possibilite a avaliação pelos pares em nenhuma IES.

Para Black e Wilian (1998), avaliar não é uma prática só do professor, pois envolve, principalmente, os alunos que não devem agir passivamente, porém precisam refletir e revisar os resultados dessa ação. Os autores enfatizam a importância de os alunos participarem desse processo, tendo a capacidade de se autoavaliar e identificar o que é preciso fazer para qualificar suas trajetórias formativas. O sentido da autoavaliação é fazer com que o aluno assuma protagonismo em seu processo educativo, constituindo-se corresponsável da aprendizagem (SANTOS; MAXIMIANO, 2013).

Desse modo, apontamos para a necessidade de alunos e professores se tornarem parceiros corresponsáveis na aprendizagem e na avaliação. Para tanto, é preciso deixar que os discentes assumam progressivamente a responsabilidade pelo processo de avaliação e de feedback. Se partimos do princípio de que a formação de professores inclui como objetivo geral o desenvolvimento das habilidades de pensamento crítico, autocrítica, julgamento e outras habilidades para o aprendizado contínuo e autônomo, deveríamos entender também os processos avaliativos nesse sentido, possibilitando, assim, a aprendizagem desses aspectos necessários à atuação profissional.

Boud, Cohen e Sampson (1999) salientam que os alunos precisam de confiança e competência para fazer julgamentos sobre o que produzem. Para os autores, a formação deve proporcionar o desenvolvimento da capacidade de o aluno avaliar a qualidade, a integridade e a precisão do seu trabalho com relação aos padrões estabelecidos e ter a confiança necessária para expressar seus julgamentos com convicção.

O segundo grupo destaca a produção de trabalhos envolvendo: artigos e projetos de pesquisa; conversa; ficha de observação; produção de fotos, imagem, filmes e vídeos; plano de aula; portfólios; seminário; e Tecnologias de Informação e Comunicação (TICs). Esses instrumentos foram relacionados com critérios de avaliação que envolvem aspectos técnicos estruturais (prazo de entrega, formatação, qualidade etc.) e aspectos comportamentais (participação, interesse, envolvimento, presença etc.). Eles foram descritos nos planos de 
disciplinas das duas áreas de conhecimento, entretanto recebem maior peso nas de cunho didático-pedagógico e estabelecem tanto uma avaliação individual como coletiva dos alunos.

[...] os acadêmicos em dupla deverão elaborar relatório das oportunidades educação e lazer do seu próprio município numa análise crítica do modelo de política posto em prática. Os registros das observações devem ser feitos na plataforma Moodle com curiosidade acadêmica, registros fotográficos e textuais. [...] na Plataforma Moodle, a turma também discutirá, por meio da ferramenta Fórum, com acompanhamento da professora, as observações feitas na aula de campo [...] (Políticas Públicas e Legislação Educacional, ESFA).

Portfólio: contendo identidade visual da empresa acadêmica, a sua missão e seus objetivos relacionados ao mercado de trabalho. Assim como a apresentação do projeto de intervenção destinado às concedentes. Incluindo relatórios, materialização das atividades desenvolvidas [fotos e vídeos] e documentações do processo do estágio profissional [individual e coletivo] (Estágio Profissional I, UVV).

A avaliação será realizada com os seguintes instrumentos e momentos: Entrega e apresentação artística das narrativas autobiográficas de formação (Como foi a minha Educação Física no ensino fundamental?); [...] Apresentação do Seminário; Produção de texto em sala de aula com narrativas biográficas imagéticas [...] (Currículo, FVC).

O fragmento do plano de disciplina de Políticas Públicas e Legislação Educacional da ESFA tem evidenciado o modo como os professores se apropriaram da plataforma como ferramenta de auxílio nos processos avaliativos. A plataforma moodle é um ambiente virtual de aprendizagem da instituição no qual os alunos, via on-line, realizam atividades propostas e têm acesso a conteúdos das disciplinas. É preciso salientar que o curso de Educação Física da ESFA foi o único a destacar o uso de uma tecnologia de informação e comunicação como ferramenta para avaliação dos alunos.

O curso de Educação Física da ESFA tem 90\% das disciplinas realizadas de forma presencial e $10 \%$ na modalidade a distância. A plataforma digital começou a ser utilizada inicialmente como forma de flexibilizar as orientações de TCC e como repositório das produções das disciplinas Estágio e Oficinas. Hoje, o uso da plataforma se estende a todas as disciplinas do curso.

A criação de ambientes de discussão, nos quais professores e alunos abordam e debatem sobre um tema, tem sido uma das formas de usar a plataforma para avaliar. Ela também é usada como local virtual para entrega de relatórios, fotos e acompanhamento dos processos de visitas de campo e estágios supervisionados. Esse uso assemelha-se à função do portfólio on-line, que possibilita aos alunos registrar de forma contínua suas experiências significativas do processo formativo. 
A Organização dos Estados Ibero-Americanos elaborou, em 2008, uma série de metas educativas para 2021. Entre elas, apontou como objetivo que as TICs façam parte do cotidiano das formações de professores. Esses instrumentos objetivam recolher informações para oportunizar uma formação continuada do professor de acordo com o nível específico de integração das TICs que ele possui. Bona e Basso (2013) destacam que tecnologias, como fórum, e-mail, wikis e chats, são as mais exploradas, por permitirem uma comunicação síncrona e assíncrona entre os sujeitos envolvidos no processo educativo. Esses autores concluíram que as atividades com o uso dessas tecnologias, quando são bem planejadas e mediadas pelo professor, possibilitam o registro constante das interações e construções dos alunos, subsidiando uma avaliação formativa que possibilita a regulação da aprendizagem.

O fragmento do plano de Estágio Profissional I tem destacado o uso do portfólio como instrumento avaliativo. Segundo Villas Boas (2004), é um registro avaliativo que permite aos alunos participar de forma ativa da construção da prática avaliativa e, com ela, elaborar apontamentos do desenvolvimento de suas aprendizagens. Esse registro é um meio de reflexão que representa as ligações que possibilitam a produção de sentidos à projeção de processos de ensino e aprendizado, estabelecidas entre ações e crenças, pensamentos e ações.

A disciplina Currículo da FVC tem apresentado uma variedade de instrumentos avaliativos, como o uso de narrativas (auto)biográficas, produção de apresentações artísticas, seminários e imagens. Essa inventividade tem favorecido que os estudantes se expressem suas aprendizagens ao valorizar diferentes saberes, deslocando a importância de avaliar o que se ensina para a produção de sentidos sobre o ensinado.

Essas ações têm reportado o modo como os estudantes se relacionam com os saberes trabalhados e valorizam o protagonismo do aluno em formação. Isso sinaliza para outras maneiras de se pensar a avaliação na formação de professores de Educação Física, bem como para a própria orientação do trabalho pedagógico do professor.

O terceiro grupo tem privilegiado a avaliação em grupo, valendo-se de instrumentos como produção de eventos, festivais e torneios; simulação docente; e situações-problema. Geralmente estão associados a critérios de aprendizagem do conteúdo (capacidade de argumentação, síntese e articulação do conhecimento) e comportamentais (postura, envolvimento, condução, comprometimento etc.). Esses instrumentos estão diretamente ligados a momentos de atuação profissional. São destacados principalmente pelas disciplinas de formação específica de cunho didático-pedagógico e cultural do movimento humano. 
Harris e Brown (2013) e Keaney (2013) destacam a importância da avaliação em grupo e argumentam que ela não deve se relacionar apenas com os conteúdos específicos do curso e com os objetivos de aprendizagem, mas deve incluir as habilidades necessárias ao contexto externo à sala de aula, como: colaboração, trabalho em equipe e aprendizado autônomo.

Entretanto, Khuzwayo (2018) alerta para as inconsistências e a falta de confiabilidade na atribuição das notas dos alunos que participaram de tarefas em grupo. Em estudo empírico realizado no curso de formação de professores na África do Sul, o autor ressalta que as competências de cada aluno não podem ser determinadas com segurança ao atribuírem uma marca geral, pois estudantes com baixo desempenho e envolvimento nas atividades coletivas poderiam receber notas altas, não sendo proporcionais às performances individuais.

Para verificar a confiabilidade, os professores participantes do estudo realizaram entrevistas e testes orais individualmente com os alunos para identificar aqueles que participaram ativamente no processo coletivo e os que não eram merecedores de receber notas altas. Como sugestão, o estudo recomenda que as tarefas realizadas pelos grupos estejam cuidadosamente alinhadas com técnicas de moderação para verificar autenticidade e justiça na alocação de pontuações.

Neste terceiro grupo, os instrumentos avaliativos estão vinculados às situações práticas, nas quais o aluno é colocado na função de docente e, a partir de seu desempenho com o grupo na condução e resolução do problema, é avaliado.

Atividade prática de construção, planejamento de aula e simulação docente. [...]. Elaborar e participar do Festival Iê Capoeira (Capoeira na Escola, FVC).

Os acadêmicos deverão elaborar e aplicar um Programa de Treinamento a um grupo de 'atletas', dentro de uma Instituição Escolar escolhida. Serão levados em consideração para avaliação: os testes físicos; a funcionalidade dos métodos; a periodização; as intervenções periódicas (Treinamento Esportivo em Ambientes Educacionais, ESFA).

Elaboração, realização e avaliação do torneio de handebol. [...] será observada a capacidade de sistematização e criticidade dos conhecimentos adquiridos, bem como a clareza e relatividade com o tema abordado nas vivências simuladas, e a capacidade de interação, resolução de problemas e criação de propostas nas situações apresentadas (Práxis dos Esportes Coletivos, ESFA).

Construção, planejamento e vivência das aulas práticas-teóricas-práticas [...] realização de trabalhos de filmagem e análise das intervenções no cotidiano escolar (Avaliação Educacional, UVV).

Os fragmentos dos planos dessas disciplinas têm revelado um movimento que foge das práticas avaliativas tradicionalmente desenvolvidas no ensino superior. Ganham destaque a 
simulação docente, intervenções no cotidiano escolar, realização de torneio, vivências simuladas e aplicação de um programa de treinamento. Ou seja, os momentos de atuação docente são considerados instrumentos avaliativos, tendo como critérios: participação, envolvimento, capacidade de organização da aula e postura profissional.

É preciso destacar que geralmente essa avaliação tem sido articulada a outros instrumentos de registro, como entrega de plano de aula, portfólios, relatórios, planejamento etc. Nesse sentido, fica evidente a necessidade de pensar ferramentas de registro que possibilitem que tanto os professores como os alunos registrem essas práticas servindo como alicerce para o juízo de valor e feedback.

De modo geral, as práticas avaliativas descritas nos planos evidenciam a urgência de a formação inicial de professores explorar outros instrumentos que permitam aos alunos terem momentos de prática com a avaliação, acompanhados, orientados e com critérios previamente acordados, para julgar seu próprio trabalho e o de outras pessoas. Assim, entendemos, como desejável para a formação inicial de professores, assumir a avaliação a partir do princípio de corresponsabilidade entre professores e alunos, tanto para o juízo de valor como para uma tomada de decisão. Esse movimento, quando projetado em uma sequência interligada, construtiva e organizada, pode proporcionar um envolvimento substancial do aluno ao longo do tempo nos processos avaliativos e, consequentemente, na melhoria de sua aprendizagem.

\section{Considerações finais}

O objetivo deste artigo foi compreender como são prescritas as práticas avaliativas em todas as disciplinas que compõem a matriz curricular de três cursos de formação de professores em Educação Física das instituições privadas do Estado do Espírito Santo e suas implicações para a constituição dos saberes docentes.

Levando em consideração os critérios avaliativos adotados pelos cursos, os aspectos técnico-instrumentais tiveram maior peso, representando $45 \%$; em seguida, com $40 \%$, os aspectos comportamentais; e 15\% relacionados com o ensino e com a aprendizagem.

Grande diversidade de instrumentos avaliativos foi prescrita. As disciplinas de formação ampliada privilegiaram as avaliações individuais com ênfase na escrita e no uso da prova. Já as disciplinas de formação específica apresentaram maior variedade e dão maior peso às avaliações em grupo com o uso de instrumentos, como portfólio, seminário, TIC, foto e filmagem, simulação docente etc. Destacamos um movimento que, independentemente da área de conhecimento, tem, na prática avaliativa, buscado compreender o modo como os 
alunos articulam os saberes aprendidos nas aulas com situações práticas de atuação profissional.

Assim, enfatizamos a necessidade de a formação de professores estar focada na aprendizagem e assumir instrumentos e critérios avaliativos que envolvam os alunos. Para tanto, é preciso entender que, ao formar o professor, toda avaliação deve consistir em uma atividade de aprendizagem significativa em si mesma, e não apenas ser considerada como instrumento que permite serem feitos julgamentos sobre o que foi aprendido.

A partir dos achados deste estudo, sinalizamos a importância de pesquisas que investiguem como a avaliação educacional é discutida nas diferentes disciplinas que compõem a matriz curricular dos cursos de formação de professores em Educação Física no âmbito nacional e nos países da América Latina.

Salientamos, também, a necessidade de formação continuada sobre avaliação para professores que atuam no ensino superior na formação de novos docentes. Entendemos que boas práticas avaliativas desenvolvidas no processo de formação favorecem a aprendizagem dos alunos, como também possibilitam a apropriação de novos modelos de avaliação para futura prática docente. Entretanto, destacamos que o simples fato de ter vivenciado boas práticas avaliativas na formação inicial pode não ser suficiente para assumi-las em uma docência futura. Essas experiências devem estar acompanhadas de formação específica sobre o tema e momentos de experiência com a prática avaliativa durante a graduação.

\section{REFERÊNCIAS}

BLACK, Paul; WILIAM, Dylan. Assessment and classroom learning. Assessment in Education: Principles, Policy \& Practice, Princeton, v. 5, n. 1, p. 7-74, 1998.

BLOCH, Marc L. B. Apologia da história ou o ofício do historiador. Rio de Janeiro: Jorge Zahar, 2001.

BONA, Aline S. D.; BASSO, Marcus V. A. Portfólio de matemática: um instrumento de análise do processo de aprendizagem. Bolema, Rio Claro, v. 27, n. 46, p. 339-416, 2013.

BOUD, David; COHEN, Ruth; SAMPSON, Jane. Peer learning and assessment. Assessment and Evaluation in Higher Education, v. 24, n. 4, p. 413-426, 1999.

CHARLOT, Bernard. Da relação com o saber: elementos para uma teoria. Porto Alegre: Artes Médicas Sul, 2000.

CECHELLA, João Carlos. A avaliação em educação física: uma nova perspectiva. Revista Kinesis, Santa Maria, n. 8, p. 65-76, 1991. 
DARIDO, Suraya C. Avaliação em educação física na escola. In: DARIDO, Suraya C.; RANGEL, Irene C. A. (org.). Educação física na escola: implicações para a prática pedagógica. Rio de Janeiro: Guanabara Koogan, 2011.

DELUCA, Christopher; KLINGER, Don A. Assessment literacy development: identifying gaps in teacher candidates' learning. Assessment in Education: Principles, Policy \& Practice, v. 17, n. 4, p. 419-438, 2010.

ESTEBAN, Maria Teresa (org.) Avaliação: uma prática em busca de novos sentidos. Rio de Janeiro: DP\&A, 1999

FOUCAULT, Michel. Vigiar e punir. Petrópolis: Vozes, 1977.

FROSSARD, Matheus L.; CASSANI, Juliana M.; STIEG, Ronildo; PAULA, Sayonara C.; SANTOS, Wagner. Appropriations of the evaluation practices for teaching of undergraduate students in physical education, Journal of Physical Education, v. 29, p. 1-13, 2018.

FUZII, Fábio T. Formação de professores de educação física e avaliação: investigando a reestruturação curricular dos cursos de licenciatura. 2010. 197 f. Dissertação (Mestrado em Pedagogia da Motricidade Humana) - Programa de Pós-Graduação em Ciências da Motricidade, Universidade Estadual Paulista, Rio Claro, 2010.

GATTI, Bernadete A. Formação inicial de professores para a educação básica: pesquisas e políticas educacionais. Estudos em Avaliação Educacional, v. 25, n. 57, p. 24-54, 2014.

GIMENEZ, Roberto. Século XIX: conquistas e desafios na formação de professores de educação física: In: GIMENEZ, Roberto; SOUZA, Maurício T. (org.). Ensaios sobre contextos da formação profissional em educação física. Várzea Paulista, SP: Fontoura, 2011. p.73-82.

GINZBURG. Carlos. Mitos, emblemas, sinais: morfologia e história. São Paulo: Companhia das Letras, 1989.

HAMODI, Carolina; LÓPEZ-PASTOR, Victor M.; LÓPEZ-PASTOR, Ana Teresa. If I experience formative assessment whilst studying at university, will I put it into practice later as a teacher? Formative and shared assessment in Initial Teacher Education (ITE). European Journal of Teacher Education, v. 40, n. 2, p. 1-20, 2017.

HARRIS, Lois R.; BROWN, Gavin T. Opportunities and obstacles to consider when using peer- and self-assessment to improve student learning: case studies into teachers'

Implementation. Teaching and Teacher Education, v. 36, p. 101-111, 2013.

HOFFMANN, Jussara. Pontos e contrapontos: do pensar ao agir em avaliação. 7. ed. Porto Alegre: Mediadora, 2002.

KEARNEY, Sean. Improving engagement: the use of 'authentic self-and peer-assessment for learning' to enhance the student learning experience. Assessment \& Evaluation in Higher Education, v. 38, n. 7, p. 875-891, 2013. 
KHUZWAYO, Mamsi E. Assessment of group work in initial teacher education and training. South African Journal of Education, v. 38, n. 2, 2018.

MARTINS, Pura Lúcia O. Didática teórica/didática prática: para além do confronto. 7. ed. São Paulo: Loyola, 2002.

MENDES, Olenir M. Formação de professores e avaliação educacional: o que aprendem os estudantes das licenciaturas durante sua formação. 2006. 166 f. Tese (Doutorado em Educação) - Faculdade de Educação, Universidade de São Paulo, São Paulo, 2006.

NASCIMENTO, Adriano R. A.; MENANDRO, Paulo R. M. Análise lexical e análise de conteúdo: uma proposta de utilização conjugada. Estudos e Pesquisas em Psicologia, v. 6, n. 2, p.72-88, 2006.

NÓVOA, António. Os professores e a sua formação. Lisboa: Dom Quixote, 1992.

NOVOA, António. Firmar a posição como professor, afirmar a profissão docente. Caderno de Pesquisa [on-line], v. 47, n. 166, p. 1106-1133, 2017.

PASCARELLA, Ernest T.; TERENZINI, Patrick T. How college affects students: a third decade of research. San Francisco: Jossey-Bass, 2005.

PICOS, Andrés P.; LÓPEZ-PASTOR, Victor M. Haz lo que yo digo pero no lo que yo hago: sistemas de evaluación del alumnado en la formación inicial del profesorado. Revista de Educación, v. 36, p. 279-305, 2013.

ROMBALDI, Rosiane M.; CANFIELD, Marta S. A formação profissional em educação física e o ensino da avaliação. Revista Kinesis, Santa Maria, n. 21, p. 31-36, 1999.

SACRISTÁN, José Gimeno. O currículo: uma reflexão sobre a prática. Porto Alegre: Artmed, 2000.

SANTOS, Wagner dos. Currículo e avaliação na educação física: do mergulho à intervenção, Vitória: Proteoria, 2005.

SANTOS, Wagner dos; MAXIMIANO, Francine de L. Avaliação na educação física escolar: singularidades e diferenciações de um componente curricular. Revista Brasileira de Ciências do Esporte, Florianópolis, v. 35, n. 4, p. 883-896, out./dez. 2013

SANTOS, Wagner dos; ROSTOLDO Lívia; CASSANI, Juliana; MELLO, André S.; SCHNEIDER, Omar. Avaliação na educação física escolar: construindo possibilidades para atuação profissional. Educação em Revista, Belo Horizonte, v. 30, n. 4, p. 153-179, 2014.

SANTOS, Wagner; STIEG, Ronildo; CASSANI, Juliana; VIEIRA, Aline; OLIVEIRA, Mathews; FERREIRA NETO, Amarílio. Formação de professores em educação física e avaliação: saberes teóricos/práticos. Revista Contemporânea de Educação, v. 14, n. 29, 2019. 
SANTOS, Wagner; VIEIRA, Aline O.; STIEG, Ronildo; MATHIAS, Bruna J.; CASSANI, Juliana M. Práticas avaliativas de professores de educação física: inventariando possibilidades. Journal of Physical Education, v. 30, p. 3005, 2018.

SCHNEIDER, Omar; BUENO, José G. A relação dos alunos com os saberes compartilhados nas aulas de educação física. Movimento, Porto Alegre, v. 11, n. 1, p. 23-45, 2005.

SIEBERT, Raquel S. Avaliação em educação física: uma produção da verdade disciplinar. Revista Brasileira Ciência do Esporte, Santa Maria, v. 16, n. 3, p. 151- 157, 1995.

SLUIJSMANS, Dominique M.; PRINS, Frans. A conceptual framework for integrating peer assessment in teacher education. Studies' in Educational Evaluation, v. 32, p. 6-22, 2006.

STIEG, Ronildo; VIEIRA, Aline O.; FROSSARD, Matheus L.; FERREIRA NETO, Amarílio; SANTOS, Wagner. Avaliação educacional nos cursos de licenciatura em educação física nas IES brasileiras: uma análise das disciplinas específicas. Currículo sem Fronteiras, v. 18, p. 639-667, 2018.

VILLAS BOAS, Benigna M. F.; SOARES, Sílvia L. O lugar da avaliação nos espaços de formação de professores. Caderno Cedes, Campinas, v. 36, n. 99, p. 239-254, 2016.

VILLAS BOAS, Benigna. M. F. Portfólio: avaliação e trabalho pedagógico. Campinas: Papirus, 2004.

\section{SOBRE OS AUTORES:}

\section{Fábia Maria Boreli Poleto}

Mestre em Educação Física pela Universidade Federal do Espírito Santo (UFES); professora do curso de Educação Física do Centro Universitário São Camilo - Brasil; membro do Instituto de Pesquisa em Educação e Educação Física (Proteoria). E-mail: fabiabpoleto@hotmail.com

\section{iD https://orcid.org/0000-0003-0542-8949}

\section{Matheus Lima Frossard}

Doutorando em Educação Física pela Universidade Federal do Espírito Santo (UFES); membro do Instituto de Pesquisa em Educação e Educação Física (Proteoria); bolsista de doutorado/Capes/ES. E-mail: matheusmlf1@gmail.com

iD https://orcid.org/0000-0002-2273-7535

\section{Wagner dos Santos}

Doutor em Educação pela Universidade Federal do Espírito Santo (UFES); professor do Programa de Pós-Graduação em Educação e do Programa de Pós-Graduação em Educação Física; líder do Instituto de Pesquisa em Educação e Educação Física (Proteoria); bolsista de Produtividade em Pesquisa do CNPq - Nível 2. E-mail: wagnercefd@ gmail.com

(iD) https://orcid.org/0000-0002-9216-7291 